\title{
As lições interculturais de contos tradicionais "vertidos" em literatura infantil
}

The intercultural lessons of folktales, "poured" into children's literaturel

\author{
MARGARIDA MORGADO \\ NATIVIDADE CARVALHO PIRES \\ Instituto Politécnico de Castelo Branco \\ Portugal \\ marg.morgado@ipcb.pt \\ natividadepires@ipcb.pt
}

Resumo. Os contos tradicionais, na sua, por vezes, dupla dimensão de contos de nacionalidades particulares mas também de 'contos do mundo', tendem a preservar elementos inalterados, em geral no que diz respeito a reações negativas ao diálogo intercultural, de reação à diferença e à diversidade e de representação do que constitui a justiça e injustiça social. As autoras apresentam alguns dados sobre um projeto que desenvolveram no livro Literatura Infantil e Educação Intercultural:Vivemos num Mundo Sem Esconderijos, no qual analisam formas de negociação de situações críticas em contos 'nacionais' de Portugal contidas em obras dirigidas a um público infantil e juvenil. Analisam-se os textos Histórias Tradicionais Portuguesas Contadas de Novo, A Machadinha e a Menina Tonta e - Cordão Dourado, e Fiz das Pernas Coração no quadro da literatura 'tradicional' portuguesa e das pressões culturais da lusofonia.

Palavras chave: contos tradicionais; diálogo intercultural; nação; incidentes críticos; humor.
Abstract. The myths and the legends that authors so often translate into 'world stories' of particular national contexts, tend to preserve untouched some parts of the tales from oral tradition, especially with regard to negative reactions to intercultural dialogue, reactions to difference and diversity and to representations of social justice and injustice. The authors elaborate on some findings from their published book "Literatura Infantil e Educação Intercultural:Vivemos num MundoSemEsconderijos"/"Child ren's literature and Intercultural Education: We live in a world without hiding-places", to highlight how critical intercultural incidents are presented and solved in 'national' Portuguese folktales adapted for children and young people as children's fiction. The texts analysed are essentially the following: "Histórias Tradicionais Portuguesas Contadas de Novo", "A Machadinha e a Menina Tonta e o Cordão Dourado", and "Fiz das Pernas Coração" and they are written about in the context of 'traditional' Portuguese folktales under pressure from the new cultural framework of 'lusofonia', i.e. Portuguese speaking nations in the world. Key words: folktales; intercultural dialogue; nation; critical intercultural incidents; humour.

\footnotetext{
I Para citar este artículo: Morgano, M. y Pires, N. C. As lições interculturais de contos tradicionais "vertidos" em literatura infantil. Alabe 5, junio 2012 [http://www.ual.es/alabe]
} 


\section{Introdução: do português à lusofonia}

Os contos tradicionais de um território, tantas vezes transformados em 'contos nacionais' dirigidos a um público infantil, condensam formas de identificação cultural que perduram no imaginário e nas conceções mentais de quem os leu ou ouviu - são uma espécie de 'narrativas em que falamos intimamente entre nós', que parecem querer reunir os leitores em torno de uma cultura comum num quadro paradigmático dos nacionalismos oitocentistas. No contexto da literatura infantil os contos e histórias tradicionais portuguesas constituem muitas vezes formas de identificação cultural locais e nacionais, por oposição a outras culturas nacionais, locais e de outros tempos. A ideia de representatividade e de adaptação para leitores modernos combinam-se para tornar uma identidade 'nacional' acessível ao leitor e, como todo o processo de identificação, constrói-se a partir do que é diferenciador dessa identidade em relação a presumíveis outras.

Sabemos que não existem identificações culturais homogéneas, estáveis, unas ou estáticas e que a ideia de ‘contos tradicionais portugueses’ será uma amálgama de coisas diversas, e sabemos também que é previsível que os horizontes de expectativas de leituras no espaço e no tempo determinem a produção de novas perspetivas de um mesmo texto, tanto da parte de quem os reescreve como da parte de quem os lê e publica. No entanto, quando se editam coleções com o título de "Contos Portugueses" ou "Histórias Tradicionais Portuguesas" para crianças parece querer-se delimitar no tempo e no espaço uma ideia de nação e de herança cultural nacional que vale a pena preservar.

O que caracteriza a dimensão nacional neste tipo de textos - que tanto possuem em comum ao nível do enredo e das personagens com tantos outros contos que circulam pelo mundo e que são apropriados por outras culturas nacionais - (e aqui restringimos a nossa análise aos seguintes textos: Histórias Tradicionais Portuguesas Contadas de Novo, A Machadinha e a Menina Tonta e o Cordão Dourado, e Fiz das Pernas Coração) são traços generalizantes toponímicos da geografia de Portugal continental, de um passado rural, da sua fauna e flora, de hábitos culinários e ritmos de vida e de trabalho, que condensam assim o que os torna assimiláveis pelo leitor como sendo ‘português', raiando formas estereotipadas e nostalgicamente reevocadas.

A ideia de 'nação', neste caso configurada a partir do adjetivo que qualifica as histórias portuguesas, deve também ser pensada a partir de alguns dos pontos enunciados por Homi Bhabha em Nation and Narration (I990) nomeadamente: Primeiro, que os atos de consolidação de narrativas de origens (vide 'tradicionais') são simultaneamente momentos de exclusão e de repúdio cultural que jogam maiorias contra minorias (Bhabha, I990: $5^{-6)}$ e que neste caso vão opor o campo à cidade, a ruralidade à urbe, a vida no passado à vida no presente. Segundo, que a partir de meados do século XIX, a ideia de nação, e os discursos sobre a nação preenchem o vazio deixado por comunidades e

\footnotetext{
${ }^{2}$ Este artigo é parcialmente baseado no livro das autoras intitulado Educação Intercultural e Literatura Infantil. Vivemos num Mundo sem Esconderijos (Lisboa: Colibri, 2OIO), V. Bastos, G., Ler o mundo através dos libros. Allabe 4 , diciembre 2OII [http://www.ual.es/alabe]
} 
populações desenraizadas porque obrigadas a migrar do campo para as cidades (Bhabha, I990: 29I), pelo que será legítimo perguntar a propósito da utilização de contos 'tradicionais' na literatura infantil, que propósito educativo servem e se não correm o risco de representarem realidades esvaziadas de significação para as crianças do século XXI. Terceiro, que a ideia de 'nação' se constrói por intermédio de textos e que é um espaço imaginado - Benedict Anderson (r99I) fala em 'comunidade imaginada' - um espaço que precisa de ser alimentado e reproduzido. O reconto de histórias 'tradicionais portuguesas' é uma forma de alimentar o espaço imaginário do que é 'ser-se português' através da estabilização de um determinado património cultural oitocentista junto das crianças. As recentes edições de literatura infantil publicadas em Portugal que visam a reconstituição dessa memória podem ser interpretadas como um modo de procurar fazer sentido da nacionalidade em tempo de grande instabilidade cultural, de multiculturalidade e de desejável redefinição da 'cultura nacional' a partir da dialética entre narrativas modernas, narrativas do passado, mas também narrativas coloniais, pós-coloniais e 'nativas' (Bhabha, I990: 330) - veremos um exemplo disso mais à frente.

Existem muitas oportunidades de ler nestes textos para crianças, que se afastam significativamente dos conceitos canónicos de ‘mito’ e ‘lenda’ por não se oferecerem aos leitores como explicação para factos históricos reais, religiosos ou sobrenaturais, incidentes críticos de confronto intercultural, que opõe pessoas e sociedades numa luta ou conflito de opiniões, interesses, ideias e práticas. Nesses incidentes encontramos aquilo que é o ponto central desta exposição e o seu argumento: os mitos e lendas vertidos em 'contos tradicionais' da literatura infantil existem numa área de conflito entre um impulso criativo e editorial de preservação de uma literatura tradicional, pressuposta imutável ao longo dos tempos apesar de variações e variantes, e um impulso contrário, de abertura à diversidade cultural e à necessidade de a literatura infantil se envolver de forma direta com os problemas e as tensões do tempo das crianças. Prova disto serão a publicação, em paralelo, de coletâneas de contos tradicionais portugueses e 'outras' histórias tradicionais que começam a surgir em coletâneas e que em vez de 'portuguesas' são 'em português'. Estas representam ênfases ‘pós-coloniais' como as que ficam patentes nas coletâneas construídas a partir do conceito de lusofonia, do português de territórios situados noutros continentes, como é o caso de Rãs, Príncipes e Feiticeiros. Oito histórias dos oito países que falam português, de Ana Maria Magalhães e Isabel Alçada (2008). A coletânea reúne contos tradicionais e lendas sobre a origem geográfica do território. Cada história é ligada a um território que é ou foi português: Angola, (“A Rã Mainu”), Brasil ("Os Amores de Uirapuru, o Pássaro Vermelho"), Cabo Verde (“O Senhor maio”), São Tomé e Príncipe ("Cantagalo”), Guiné (As Filhas de Faram”), Moçambique ("O Macaco e o Tubarão") Portugal ("O Príncipe Encantado") e Timor ("O Rapaz e o Crocodilo”). Estas coletâneas alimentam a ideia de identidade nacional não a partir do conceito de 'nação’ mas do conceito da língua, do português como língua partilhada em territórios geográficos dispersos pelo mundo; imaginam um espaço que vai para além das fronteiras geográficas de Portugal continental e procuram estabilizar um património contístico que tem 
em linha de conta a progressiva multiculturalidade de Portugal em diálogo com espaços colonizados no passado por portugueses e a globalização.

No entanto, não será de desprezar uma análise mais aprofundada e crítica de como são abordados alguns elementos interculturais nas coletâneas 'tradicionais' "portuguesas' para crianças, nem estratégias de ativação da leitura, pois elas nos demonstrarão que algumas estratégias narrativas e/ou a ilustração, podem contribuir para levar o jovem leitor a recolocar o conto tradicional no seu próprio tempo e a reapreciá-lo com a distância crítica necessária para que esses contos existam com relevância para o presente.

\section{Uma perspetiva intercultural}

No quadro da teorização e práticas de educação intercultural é central a ideia de que existem relações de poder, também elas manifestas aos níveis de quem lê o quê, do que é publicado e do que é valorizado como literatura infantil e juvenil, ou incluído nos textos canónicos da educação (como seja o caso de Plano Nacional de Leitura). Neste texto interessa-nos focar dois tipos de questões da educação intercultural: a relação de identidade com alteridade, por um lado, e a equidade e justiça social, por outro. Ora, estes são dois aspetos culturais e políticos que têm sido abordados de modo muito diferente no presente, por oposição ao passado, à luz de correntes ideológicas de multiculturalismo conservador, liberal e crítico (Botelho e Rudman, 2009; Sleeter e Grant, 2003; Gorski, 2009), que rejeitam paradigmas culturais assimilacionistas, em favor de políticas de diferenciação e discriminação positiva, desocultação de relações de poder instaladas e naturalizadas, e transformação radical da sociedade para promover a equidade e a justiça social de grupos e indivíduos historicamente oprimidos.

Desta perspetiva intercultural reparámos que as versões recém-publicadas de alguns contos tradicionais para crianças, entre as quais se encontram Histórias Tradicionais Portuguesas Contadas de Novo (Torrado e Lopes, 2002), A Machadinha e a Menina Tonta e o Cordão Dourado (Vieira e Silva, 2006), e Fiz das Pernas Coração (Gomes e Wociechowska, 2000), tendem a preservar certas pressuposições culturais assimilacionistas, preconceitos e estereótipos inalterados e que, em geral, quando apresentam incidentes culturais, pessoais e políticos pertinentes ao viver contemporâneo, ou não se preocupam em apresentar revisões e reescritas que possam promover a educação intercultural, no sentido em que a descrevemos acima, ou dão um primeiro passo nesse sentido ao usar de humor, de ironia, de jogos de palavras, deincerteza ou ambivalênciade sentidos, ou de intertextualidade, tanto ao nível do texto escrito como da imagem, que desestabilizam a ilusão de segurança do leitor relativamente ao que lê e que o desafiam a adotar posturas mais reflexivas ou distantes do narrado.

Este tipo de contos é geralmente sintético e claro quanto aos valores que proclamam de como se deve abordar a alteridade, a diferença e a diversidade e o que é justo ou injusto, bem como o que se deve fazer para corrigir o que está mal. Existem, nos contos 
'portugueses' ou 'nacionais', 'outros' invariavelmente representados como unificados, homogéneos, estáticos, caricaturas de um modo de estar, presos a um espaço-tempo definido, geralmente o espaço rural e um passado não muito distante, que contrastam com a experiência de grande parte dos leitores, concentrados num viver urbano em grandes centros.

Bastará analisar formas de representação do diálogo intercultural, da reação à diferença e à diversidade e da justiça social por intermédio da ideia patente em alguns dos textos de ‘correr mundo' ou de utilização personagens e situações que podem ser consideradas diferentes do que seria expectável pelo herói, para encontrar linhas de falha (faultlines na proposta de Sinfield (I992) por analogia com placas tectónicas) na construção textual que permitem ativar leituras alternativas de promoção da interculturalidade. Pelo facto de podermos não estar, por vezes, perante o politicamente correto, não significa que educadores e os professores não possam introduzir olhares críticos que permitam atualizar os textos para valores de apreço da interculturalidade.

É refletindo sobre os modos de configuração dos momentos de tensão e conflito cultural das histórias e combinando-os com numa sugestão de Appadurai (2009) de negociação em torno de cada situação crítica (de deficit democrático, de necessidade de migração, de discriminação, de pobreza, de ameaça ambiental ou à vida humana digna) que encontramos, nestes pequenos contos e nos seus incidentes, matéria de reflexão sobre a interculturalidade. A partir da situação crítica e dos modos específicos de diálogo ou de resolução encontrados propomos leituras capazes de evidenciar: a diversidade e a diferença, a injustiça e justiça.

Eis algumas das questões que podemos formular: Quem são os 'outros' por oposição a 'nós'? Quão homogénea é a representação dos ‘outros'? Por que razão? Historicamente quais as práticas sociais, históricas e discursivas que se intersetam na literatura infantil para propor uma versão particular da realidade? Quais as formas mais usuais de representação da diversidade? São frequentes as situações de injustiça como forma de ameaça à vida humana digna? Que tipo de representações de formas de organização social em termos de situações de ‘injustiça', bem como dos modos de 'fazer justiça' encontramos com maior frequência? Qual a relação entre ideologia e topografia: que calamidades ameaçam a perda de modos habituais de uma personagem se sentir em casa? Como 'habitam' as personagens novos espaços ou os mesmos espaços de forma diferente? Qual o impacto de novas realidades, perspetivas e modos de ver? O que significam culturalmente encontros e conflitos: criam-se fronteiras, limites, pontes, casamentos e alianças (O’Sullivan, 2005: 38)?

Este enfoque de análise é atravessado nestas histórias por outras relações de poder assentes em variáveis de classe (os ricos contra os pobres; os nobres contra os camponeses, senhor e criado); de género (homens e mulheres; maridos e esposas, homens comuns e criaturas sobrenaturais, ...); de idade (o velho contra o jovem, o grande contra o pequeno); e de capacidade (espertos contra idiotas, 'bonitos' contra 'feios', inteligentes contra menos inteligentes, honestos contra ladrões e mentirosos, espertos contra mais espertos ainda). 
Existem muitos modos de configuração da diferença e da diversidade: pela descrição toponímica e de traços paisagísticos, pelos nomes das personagens e pelas suas atividades; pela configuração de situações que apresentam incorreções ou perversões do que é considerado correto e adequado ou configurando pontos de vista alternativos para determinadas personagens ou situações. A diferença pode ser construída a partir de situações reais de injustiça (como perseguições aos judeus, a dificuldade de acesso de crianças à educação ou a descriminação étnica e racial), ou a partir da idealização de realidades alternativas. A diferença de certas personagens em termos das suas aptidões (físicas e intelectuais) para viver o mundo com 'normalidade' despoleta peripécias que causam o riso de quem as lê, mas descreve as dificuldades de quem se sente diferente ou é percebido como diferente pelos outros.

\section{A diferença do espaço/t tempo do passado em relação com o presente}

Analisemos agora com um pouco mais de detalhe um primeiro aspeto dos contos enunciados supra: o da representação do espaço/tempo português de alguns contos como diverso do espaço/tempo presente.

Na introdução a Fiz das Pernas Coração, Gomes (2000: 9-IO) estrutura a 'tradição’ dos contos ‘tradicionais portugueses’ na oposição entre a cidade e o campo: o 'menino da cidade' e 'a aldeia'; e na oposição entre o jovem e os idosos, o masculino e o feminino: 'um menino da cidade’ e 'a mãe e umas tias velhas'; existe uma terceira oposição entre os que pertencem a um lugar e os que vêm de fora até esse lugar: entre as gentes 'nascidas e vividas na aldeia' e, por um lado, 'o menino da cidade' e, por outro, 'uma mulherzinha vinda de longe’. O passado torna-se o lugar do repositório de contos e histórias a partir do qual se definem 'outros' tempos, 'de outras tias e avós' e de outros mundos que assustavam, encantavam e faziam rir. 'Era o tempo em que os mais velhos conheciam um nunca acabar de lendas, fábulas, contos e contarelos”. É a partir deste passado, rural, feminino, que alia o contar das histórias a tarefas domésticas como a costura, que se estabelece uma tradição familiar de avós para netos, do campo para a cidade e do passado para o presente que caracterizam muitas das coletâneas de contos tradicionais portugueses recontados. As marcas desta origem são reforçadas pelo glossário que, nas páginas 82 e 83, esclarece termos botânicos, zoológicos e objetos utilizados ao longo do texto e cujo sentido terá caído em desuso. A tradição é igualmente reforçada pelo paratexto no final da coletânea que filia a recolha na tradição oral e em coletâneas anteriores como Contos Populares Portugueses (I879), recolhidos por Adolfo Coelho, Contos Tradicionais do Algarve (I90о), recolhidos por Ataíde Oliveira, e Contos Populares Portugueses (г9го) recolhidos por Consiglieri Pedroso, entre outros.

Em “O Menino Grão de Milho” (Torrado e Lopes, 2002: I7-28) o leitor é confrontado com uma aldeia, famílias com filhos, a lida do campo com o pai, a lavrar, o carro de bois cheio de lenha, a mãe a empilhar os cavacos, o pai boieiro, os lameiros à margem 
do rio e as lavadeiras - todos falam de um Portugal de ontem, rural, nostálgico onde se situam as histórias da tradição portuguesa.

Os espaços das histórias portuguesas em Histórias Tradicionais Portuguesas Contadas de Novo (Torrado e Lopes, 2002: 5-I6) são, na história de "O macaco do Rabo Cortado," lugares de um quotidiano do passado; são também locais e modos de organização social do espaço que já se encontram em desuso: o forno de lenha para cozer o pão, as paredes das casas com janelas e portas debruadas de branco - comer sardinhas em cima do pão, etc.

O mesmo acontece em "A História da Carochinha e do Infeliz João Ratão", cujas ilustrações representam as grandes rochas graníticas do interior beirão português (idem: 3I), bem como as casas brancas alcandoradas nas rochas (idem: $3^{6-37)}$. Em "O Menino Grão de Milho’ (idem: I7-28) uma aldeia, famílias com filhos, a lida do campo com o pai, a lavrar, o carro de bois cheio de lenha, a mãe a empilhar os cavacos, o pai boieiro, os lameiros à margem do rio e as lavadeiras - todos falam de um Portugal de ontem, rural, nostálgico onde se situam as histórias da tradição portuguesa.

Em “A Nau Catrineta Que Tem Muito Que Contar” (idem: 3I e 59-7o) evocam-se os descobrimentos portugueses por intermédio da representação textual e visual da nau e definem-se as terras de Portugal - contra as de Berberes e de Espanha - por uma enumeração de traços da morfologia do território, profissões e lugares: rios, lavadeiras a lavar, fornos, padeiras, açougues e carniceiros, casinhas alvas com lareiras, peixinho a fritar, taberneiras, pipas de vinho, um laranjal.

Como vimos, em muitas das histórias de coletâneas de ‘contos tradicionais' recontados a crianças o espaço/tempo de narração evoca uma descrição toponímica e de traços paisagísticos que remetem invariavelmente para um passado rural. A diferença assenta também nos nomes das personagens e nas suas atividades em espaços de troca comercial; em “A Nau Catrineta Que Tem Muito Que Contar” (idem: 2002: 59-70), as personagens são caracterizadas pelo habitus profissional: uma barbearia como espaço de encontro entre homens, homens à conversa numa esquina, uma peixaria, a canastra de sardinhas de uma peixeira ambulante, o padeiro à porta da padaria.

\section{A 'diferença' como ausência de 'normalidade'}

A diferença, enquanto ausência de normalidade constitui, como expectável, o ponto de partida de muitos contos. Pode partir de incidentes incorretos ou perversóes do que é considerado correto e adequado. Em "O Macaco do Rabo Cortado" (Torrado e Lopes 2002: 5-I6), o macaco mariola anda de bata e sacola a fingir que vai à escola. Vaidoso e corajoso, segue o impulso das suas ações: manda cortar o rabo, arrepende-se, quere-o de volta; leva a navalha do barbeiro. Dá a navalha a uma peixeira e quando a quer de volta e não lha dão, leva uma canastra de sardinhas, e por aí fora, até se ir embora para Madrid porque ali (no espaço português) não se insere e só faz disparates. 
Em “O Menino Grão de Milho’ (idem: I7-28) começa por se apresentar uma situação familiar crítica muito comum: uma família sem filhos, aludindo ao silêncio que rodeia o não acontecimento. $\mathrm{O}$ autor fá-lo de forma humorística e com um piscar de olhos à condição de ser necessário a família ter filhos para haver história:

Era uma vez um casal sem filhos.

Pronto, está tudo dito, fora o que fica por dizer. À falta de continuação que se veja, esta história emperra e acaba, logo às primeiras linhas. Curta e triste seria. (Torrado e Lopes, 2002: I7)

A diferença de certas personagens em termos das suas aptidões (físicas e intelectuais) para viver o mundo com 'normalidade' despoleta peripécias que causam o riso de quem as lê, mas simultaneamente descreve as dificuldades de quem se sente diferente ou é percebido como diferente pelos outros. Em "Senhoras da Mantinha de Seda," da coletânea Fiz das Pernas Coração (Gomes e Woichiechowska, 200o), o filho aparvalhado de uma senhora bate na testa do juiz porque nela aterra uma mosca. Tinha vendido o mel às moscas, tinha-se queixado ao juiz que umas senhoras de mantinha de seda o tinham roubado e ele dissera-lhe 'quando as encontrar atire-lhes uma boa paulada'. O motivo do rapaz tolo repete-se em relação aos contos de "Pedro Malasartes" e "Pedro Malasartes e o Homem de Visgo"(Gomes e Woichiechowska, 200o): ele é filho de uma pobre mulher e é tolo porque nunca fazia nem dizia nada acertado. Em consequência das suas tolices leva tareias.

A diferença pode radicar também, na forma física, como na história do "Príncipe Bezerro" (idem) ou d" "O Menino Grão de Milho", que era anormalmente pequeno. A existência do menino é marcada pelo isolamento porque a convivência com os outros meninos tinha criado situações de perigo para a sua integridade física "a matulagem resolvera metê-lo em aventuras, destinando-o a piloto de uma jangada de rolhas" (Torrado e Lopes, 2002: I8). E é marcada pela troça das lavadeiras que o querem arrecadar 'pendurado por um atilho no refolho do peitilho’ (idem: 2I).

Convenhamos que não são as representações politicamente mais corretas de como lidar com a diferença e bastaria comparar estes exemplos com coletâneas de histórias não tradicionais como as compiladas por Fernando Nobre, em Histórias que Contei aos Meus Filhos (Nobre e Serra, 2008) para perceber que há maneiras mais proveitosas de representar a diferença.

Contudo, analisar a construção da diferença nestes contos pode ajudar os pequenos leitores a pensar a interculturalidade, despoletando perguntas do tipo:

A) Imagina que eras anormalmente pequeno. Como seria diferente a tua vida do quotidiano? Imagina uma versão cómica e uma versão séria de 24 horas. 
B) Lê “O Menino Grão de Milho' (Torrado e Lopes, 2002: I7-28); e "Joanico" (Lisboa, 1993: 4I-50). Compara as duas histórias em relação a:o que sentem os meninos anormalmente pequenos; o que fazem; como os outros os tratam; o tom da história; o que tu sentes ao ler as histórias.

\section{Para fora das fronteiras nacionais}

Em muitos dos contos ditos tradicionais portugueses também acontece às personagens correr mundo e esta, que é uma noção central à interculturalidade (a mobilidade), também não se adequa às perspetivas hoje dominantes.

Nas histórias correr mundo significa, na maior parte das vezes, deixar os ambientes que se conhecem para partir à aventura, rumo ao desconhecido, mas pouco há de diálogo intercultural, troca de experiências, valorização do diferente e da diversidade.

Em “O Menino Grão de Milho' (Torrado e Lopes, 2002: I7-28) os viajantes que passam pela aldeia são uma família de cómicos. Correr mundo na definição destes viajantes é andar no verão por feiras e romarias do concelho, considerando a sua experiência a da totalidade do que há para saber do mundo:

\section{(...) e fica tudo visto - O mundo pouco maior é. (idem: 22)}

O protagonista de “O Menino Grão de Milho’ (idem: I7-28), apesar da sua pequena estatura, que o texto articula como problemática, é representado por intermédio das suas aptidões para fazer o que os outros fazem: conduzir a canga de bois e correr mundo. De aventura em aventura pelo pequeno mundo que é o campo, vai parar à tripa de uma vaca e de uma raposa e ao covil de ladrões, sendo capaz de os assustar e de ficar com o tesouro. As aventuras do menino grão de milho provocam um mundo virado ao avesso porque de dentro das entranhas do animal ele fala, assustando quem o ouve ou afugentando as presas que a raposa queria caçar; ou detrás de uma teia de aranha, assusta os maus ladrões. Neste mundo às avessas, o lavrador pensa que a vaca está doente e manda-a matar; a raposa vai limpar as tripas comendo areia de saibreira; e os ladrões imaginam um fantasma, o diabo, um papão. Muda-se a perspetiva e consegue-se outra perspetiva sobre as coisas.

Correr mundo em "A Machada Machadinha do José e da Joaquina" (idem: 47-58) é uma experiência etnocêntrica para José que só regista estranheza e tolice, corrigidas pelos seus bons conselhos: à velha com a candeia no nariz sugere que a pendure atrás da porta; aos homens que atiravam ovos a um muro para o deitar abaixo, sugere que usem picaretas; ao velho que andava com uma alcofa para apanhar o sol, sugere que substituísse as telhas do telhado por telhas de vidro; aos que queriam cortar a cabeça à noiva ou as pernas ao cavalo para ela entrar na igreja ao modo tradicional, sugere que ela se curve; ao casal que enterrava sardinhas na terra para que elas crescessem no inverno, sugere que as 
salguem, aos soldados que não se levantavam porque não sabiam de quem eram as pernas, desata a bater nas pernas. 'Que mundo de tolos' onde só o José tem razão.

Correr mundo resulta, em “Minha Mãe, Que Lindas Terras!” (Lisboa, I993: 2I25) no ato meio tresloucado do Tonito 'cismático' que sonha com 'lindas terras' e acaba por desaparecer. Regressa, porém, já velho, a casa dos pais, feito peregrino, roto e descalço, de longas barbas, para reconhecer que as terras da sua infância eram afinal as 'lindas terras' com que sonhara. "Esta é a minha terra, outra mais linda não há" (Lisboa, I993: 25). Fecha-se o círculo e nada resta da experiência de mobilidade a não ser que ela não era afinal necessária.

\section{Incidentes críticos}

A diferença pode igualmente ser construída a partir de situações reais de injustiça ou a partir da idealização de realidades alternativas. Em muitos contos o ponto de partida do enredo é uma situação injusta ou uma calamidade que interrompe a ordem normal das coisas. As calamidades são naturais (naufrágios, peste, inundações, tempestades, ventos), mas também podem ser causadas pelos homens. Por exemplo: um patrão que não pagava a um criado; um tempo longínquo em que os animais falavam, etc.

Tome-se por exemplo as relações injustas entre patrão e criado em "Um criado esperto" (Gomes e Woicieschowska, 2OOo). Neste conto encontramos uma resposta do tipo "olho por olho, dente por dente": o criado vinga-se do patrão, que não pagava aos criados, roubando-o de uma saca de dinheiro: 'Vingara assim os outros criados que não tinham recebido os seus salários'.

Situação semelhante, mas incidindo sobre a desigualdade social e a inteligência está patente na história "Dom Pimpão Saramacotão e o seu criado Pimpim” (Torrado e Lopes, 2002) que opõe classes sociais: o nobre senhor Dom Pimpão Saramacotão, que se julga muito sábio e usa linguagem obscura de tão rebuscada; e o criado, um rapaz da aldeia chamado Diogo, renomeado por Dom Pimpão o Pimpim Saramacotim. A resposta a situações de injustiça que nesta história vamos encontrar é comum a muita literatura infantil: $\mathrm{O}$ fraco vence o forte, também nas variantes de o indivíduo de classe mais baixa vencer o nobre, mas usando a manha, a argúcia, e a vantagem e não a negociação, ou o diálogo. Aliás, muitos dos enredos confirmam o problema como sendo o de incapacidade de dialogar.

A mudança de estatuto social surge neste contexto como um filão particularmente rico de humor que confirma a ascensão social como uma impossibilidade. No conto "O Doutor Grilo"(Gomes e Woiciechowska, 2000) um carvoeiro quer tornar-se estudante em Coimbra para poder comer boas coisas como os estudantes e desempenha uma série de atos tolos consecutivos até se tornar médico. Diz que estuda para adivinhão e, quando desaparece o tesouro ao rei de Portugal, os outros estudantes dizem ao rei que existe um que estuda para adivinhão. Ele adivinha que o rei esconde um grilo na mão porque se cha- 
ma Grilo. Adivinha de quem é o sangue no frasco porque usa uma expressão popular 'aí é que a porca torce o rabo' e os criados, com medo, confessam o roubo. Cura a princesa de um osso na garganta atirando-lhe bolas de manteiga e como o rei o nomeia médico, numa epidemia, diz aos doentes que 'aquele que estiver mais doente há de ser amanhã aberto para ser examinado’ e eles põem-se em debandada.

As soluções apresentadas para as situações de injustiça têm, na maior parte dos contos, pouco a ver com negociação. Algumas são de aceitação passiva do que acontece, outras de fuga, outras ainda de rebelião contra o acontecido. A correção das situações de injustiça pode incluir uma revolução de costumes, a denúncia, a resistência ativa e passiva, a ajuda e cooperação, num sentido positivo, bem como respostas mais negativas de encobrimento, suborno, dissimulação do ocorrido, mentira, trapaça. A negociação, de que conseguimos descortinar muito poucos exemplos, cobre estratégias diferentes, como sejam: o respeito e deferência por costumes diferentes; estratégias de transformação de uma realidade desagradável pela cooperação, pelo sonho, ou pela memória; cooperação entre rivais e demonstração do erro de comportamento ao outro e não apenas ao leitor.

O leitor notará que o humor e a paródia não deixam de estar presentes nos contos evocados. Vamos encontrar também o humor produzido pelo ridículo de factos e personagens; pela assimilação do melhor ao pior; pela surpresa e engano; pela situação imprevisível e impossível; pela violação das leis da natureza; pela atenção dada ao irrelevante, ao inconsequente, ao abaixamento das personagens, à desarmonia, às coisas baixas e grotescas; pela ridicularização dos defeitos e vícios. O humor e a paródia estão também presentes em representações de ‘um mundo às avessas' que, aliando esta estrutura profunda de conceção do mundo e da realidade a muitos dos aspetos anteriormente citados, visa a subversão das relações de poder instaladas (porque anula o medo daqueles que têm o poder e põem-no a ridículo, representam-no defeituoso, com vícios e fraco) e ensinam a olhar para as coisas de outra maneira e nesse sentido podem de facto promover a educação intercultural.

Estratégias úteis que poderíamos usar para promover a educação intercultural a partir destes contos seria olhar para uma série de incidentes críticos sobre injustiça e aplicação da justiça e convidar os jovens leitores a reagir. Por exemplo:

A) Havia um patrão que não pagava aos criados, que se iam embora de mãos a abanar depois de trabalhar arduamente. Imagina que eras contratado por esse patrão... o que farias? Debate em grupo 3 soluções diferentes para este início de história.

B) Lê o conto "Um criado esperto" (Gomes Woiciechowska, 200o) e "Dom Pimpão Saramacotão e o seu criado Pimpim” (Torrado e Lopes, 2002) e compara as respostas encontradas para situações semelhantes. Comenta-as em termos do que implicam para a negociação entre pessoas. 


\section{Conclusão}

Uma reflexão sobre educação intercultural a partir da análise da negociação em torno de cada situação crítica (sobretudo de ‘injustiça’ ou falta de justiça social e política) descrita nos contos acima abordados aporta conclusões interessantes para educadores e por ventura também para os investigadores de mitos e lendas nacionais. Estas narrativas reelaboradas para servir e educar um público infantil narram uma ideia de ‘nação’ no sentido em que oferecem uma comunidade imaginada para os leitores, que tanto pode ser confinada ao território português e à língua portuguesa, como à ideia de 'correr mundo' a partir de um ponto de origem (português). Reforçam, contudo, uma ideia de nação baseada no passado rural e na transmissão de tradições de avós para netos. Apesar da ideia de mobilidade que encerram, as estratégias usadas para descrever o mundo e a sua diversidade (toponímia, localização geográfica concreta, nomes de personagens, identificação de histórias a partir da sua filiação em nações e de povos), ou a interação com o que é diverso, evidenciam o regresso a locais de origem e o fechamento sobre um ponto de partida inicial.

No que toca à representação da justiça e injustiça sociais identificámos um conjunto de respostas diversas, umas mais positivas e outras mais negativas, umas politicamente corretas e outras não tanto. De um ponto de vista de educação intercultural, cabenos compreender que apesar de nem sempre estes contos veicularem as situações que permitiriam fomentar o diálogo intercultural ou a negociação intercultural e de justiça social, eles pode ser úteis para salientar a importância de justapor problemas e soluções idênticos e diferentes para melhor entender a variabilidade de respostas e a reflexão que deve estar na sua base.

Contudo, o que consideramos mais relevante e a não perder de vista para futuras investigações é a exploração e análise de ‘contos tradicionais portugueses' publicados para crianças simultaneamente como forma de divulgação do património cultural histórico nacional e como modo de reação à globalização e à diversidade cultural, que encontram na ideia de 'contos da lusofonia’ a sua razão de ser. 


\section{Referências}

- Anderson, Benedict (199I). Imagined Communities. Reflections on the Origin and Spread of Nationalism. London: Verso.

- Appadurai, Arjun (2009). Diálogo, Risco e Convivialidade. In: Podemos Viver sem o Outro? As Possibilidades e os Limites da Interculturalidade. Lisboa: Tinta da China. 2I-38.

- Bhabha, Homi K. (Ed.) (I99o). Nation and Narration. London: Routledge.

- Botelho, M. J. and Rudman, M. K. (2009). Critical Multicultural Analysis of Children's Literature. New York and London: Routledge.

- Gorski, Paul (2009). What we're teaching teachers: An analysis of multicultural teacher education coursebook syllabi. Teachingand Teacher Education 25 309-318.

- Gomes, José António (sel., int, e notas) e Wojciechowska, Danuta (il.) (200o) Fiz das Pernas Coração. Contos tradicionais portugueses. Lisboa: Caminho.

- Lisboa, Irene (1993). Queres ouvir? Eu conto. Lisboa: Presença.

- Magalhães, Ana Maria, Alçada, Isabel e Wociechowska, Danuta (il.) (2008). Rãs, Príncipes e Feiticeiros. Oito histórias dos oito países que falam português. Lisboa: Caminho.

- Nobre, Fernando e Serra, Sandra (Il.). (2008). Histórias que Contei aos Meus Filhos. Cruz Quebrada: Oficina do Livro, Sociedade Editorial, Lda.

- O’Sullivan, Emer (2005). Comparative Children's Literature. London: Routledge.

- Sinfield, Alan (1992). Faultines. Cultural Materialism and the Politics of Dissident Reading. Berkeley: University of California Press.

- Sleeter, Christine E. and Grant, Carla A. (2003). Making Choices for Multicultural Education. Five Approaches to Race, Class, and Gender. Wiley Josey-Bass Education.

-Torrado, António e Lopes, Maria João (Il.) (2002). Histórias Tradicionais Portuguesas Contadas de Novo. Vol.I. Porto: Livraria Civilização Editora.

- Vieira, Alice e Silva, Bela (2006). A Machadinha e a Menina Tonta e o Cordão Dourado. Lisboa: Caminho. 